\title{
Ndebele's Relationship with the Liberal-Humanists and an Evaluation of the Story-Telling Tradition
}

\author{
Dr Theophilus T Mukhuba
}

\author{
Senior Lecturer in English Studies, North-West University (Mafikeng campus), Mafikeng, South Africa
}

Email:11284722@nwu.ac.za

\section{Doi:10.5901/mjss.2014.v5n23p2425}

\begin{abstract}
Literature, like all the other art-forms, cannot really be seen from one point of view as it subscribes to different schools of thought, with the schools constantly at loggerheads in relation to technique and content of a narrative. But must be clear here that the role of narrative depends largely on its persistence to complexity of a given historical situation without exhausting itself by an indulgence or pre-occupation with the history itself, for then it will inevitably trap itself within that given historical timeframe. This then gives rise to a saturation of what to write about and we then end up with a genre whose main characteristic, it would seem, is repetition. This on the surface is Ndebele's stated position. This article will attempt to examine Njabulo Ndebele's relationship with the liberal-humanist tradition and how his theory of the storytelling tradition developed. It will also explore his perceptions on protest fiction with its characteristic of expressing 'mechanical surface representations. The main point here is to make a case for the relativity of all forms of literature by arguing for literary placement and criticism in context.
\end{abstract}

\section{Introduction}

Liberal-humanist literature is characterized by its claims to make itself the centre of literary perceptions. This type of literature sets standards of literary appreciation. Liberal-humanists have convinced themselves that art can only be judged by their own set standards and any literary work that falls outside the scope of their idea of art is dismissed as artistically lacking. They have made themselves the centre of literary aesthetics by promoting what they regard to be 'good art'. This 'good art' describes only their works or works similar to theirs. Every other type of literature that does not fall within this ambit is criticised as crude or immature literature.

In the South African context, liberal-humanist art pre-occupies itself by assessing the racial scenario in the country and the effects of deliberate, oppressive policies and how they affect the oppressed. Liberal-humanist literature in South Africa is, to a large extent, observation or research literature. Ndebele, in an essay titled "South African Literature and the Construction of Nationhood", makes the following statement about liberal South African literature and its tendency to portray itself as a centre of literary aesthetics: "This is a literature emerging from a society that has perceived itself as history's primary agent in South Africa" (1992:23).

Liberal literature is projected in a leisurely manner from a position of privilege. It is, as I have indicated earlier, an art-form which has very paternalistic characteristics. In South Africa, liberals write about their understanding of the aspirations of the oppressed without doing anything constructive to help alleviate the suffering of the oppressed. Ndebele makes the same point, which, incidentally also shows his position in relation to them, when he writes in the same article that:

If art plays an adversary role in society, asking disturbing questions, revealing unsettling feelings, attitudes, and experiences, then we will understand why it was writers who went further to ask the next two questions: How has what we have done to them affected them? How has it affected us? It will immediately be clear that the 'us' in the last question does not include the writers who are trapped in their own society (1992:23).

As if this were not an observation on liberal literary artists in South Africa, Ndebele becomes clinical in his analysis and elaboration in emphasis of the above point by adding:

They were born within it; it sent them to well-equipped schools; it provided them with publishing opportunities; it sanctified their language through legislation and language academics; it gave them theatres, museums, art galleries, concert halls and libraries; it arranged for them special salary scales that ensure access to a range of cultural facilities as well as the ability to buy books and newspapers; it created literary awards to honour them, it also made possible for some of them to become critics and reviewers who influence literary taste and declare standards; it protected them in law against the claims of the other, by assuring them of the privacy of residential areas legally inaccessible to the 'other'; thus 
ensuring they all socialized among themselves; it gave them passports to travel, they could meet other writers internationally; it sought to make them take for granted the elevated status of their citizenship and its attractive resulting comforts. Since they were concerned about the 'other' and the effect of the 'others' plight on their own humanity, theirs became a bi-polar existential reality of moral abhorrence accompanied by a physical inability to escape the conditions of that abhorrence (1992:24).

In the above explication of liberal-humanists and liberal literature and its privileged status in South Africa, there is obviously a tinge of bitterness in Ndebele's tone. As Ndebele has correctly observed, the liberal literary artist in South Africa, because of the conditions they have created or find themselves in, cannot escape from the cocoon which defines their literary scope. As a result, their literary art and perceptions are trapped into definable fixations.

\section{Scope of Perception}

This article does not suggest nor does Ndebele that liberal literary artists are totally incapable of seeing art outside the scope of their own literary limitations. I am simply stating a case about the historical conditions that inform the liberal's perception and his art. By this I also hoped to show Ndebele's relationship with liberal-humanists and by implication his refusal to be associated with them as his own criticism of their art testifies.

In this case, the question that needs to be asked is: If Ndebele's art is not influenced by the liberal-humanism or his immediate environmental conditions, as apparent in his distancing of himself from the liberal-humanists and what has come to be known as protest fiction, where then is it grounded? Ndebele's artistic perceptions are rooted in the fact that a work must of necessity comprise two fundamental aspects; ordinariness and complexity. In an article titled 'Rediscovery of the Ordinary' Ndebele argues for ordinariness as an essential component of the "storytelling tradition" as opposed to current portrayals of "the spectacular" in South African literature.

In response to Sipho Sepamla's defence of protest fiction, Ndebele hammers his point home by declaring:

I have listened to countless storytellers on the buses and trains carrying people to and from work in South Africa. The majority of them have woven master-pieces of entertainment and instruction. Others were so popular that commuters made sure that they did not miss the storytellers' trains. The vast majority of the stories were either tragedies about lovers, township jealousies, the worries of widows, about the need to consult medicine-men for luck at horse racing, or luck at getting a job or at winning a football match; or they were fantastic ghost stories... And we have to face the fact here: there were proportionally fewer overtly political stories. When they talked politics they talked politics. If any political concept crept into the stories, it was domesticated by a fundamental interest in the evocation of the general quality of African life in the township... In all these stories and songs, I am made conscious of Africans in South Africa, as makers of culture in their own right. I am made conscious of them as philosophers, asking ultimate questions about life, moral values, and social being (1991:33).

After this, I don't think that the point that Ndebele makes about the concept of story- telling needs belabouring. However, one should point out that Ndebele should not be misconstrued to imply that all black fiction has a total disregard for the concept of 'storytelling'. He acknowledges there is a small percentage of black South Africans who write stories that fall within the category of the storytelling format. What concerns him primarily is that protest fiction writers tend to write what Kaizer Nyatsumba, the journalist, calls "a genre of expository or journalistic fiction". This is a type of writing that is overwhelmingly concerned with an almost mechanical "surface" representation, making political cases, and, as Ndebele aptly puts it, "striking a blow for freedom".

In trying to establish a changed, relevant aesthetic for South African literature, Ndebele does not claim this aesthetic to be a new one. Rather he acknowledges that it is an art-form that has both local and international links and origins. For instance, in asserting his views on ordinariness within the storytelling tradition, he claims to have come to his realization about the over-politicized nature of contemporary black South African fiction after he had the Turkish writer, Yasher Kemal's stories. On the nature of Kemal's stories, Michael Banghon noted that:

Because Kemal understand the conventions of storytelling narrative so well, and because of his familiarity with the local storytelling tradition, he can draw his reader into an "imaginative" yet critical reflection upon the social processes of rural Turkey (2004:187).

In the article, "Turkish Tales...", Ndebele points out how he was jolted to a new awareness about literature, after he had read Kemal's stories, and particularly the way in which South African literature further "journalistic and sloganistic ambience" in its representations. Protest fiction, he claims, is repetitive in nature and has the tendency to disregard certain aesthetic values such as "complexity" and "interiority". In its exhibitionist form, protest fiction records and provides supposed answers rather than posing problems, as, claims Ndebele, Chekov would have literature do. 


\section{Ndebele's Literary Prescription}

Though Ndebele claims to understand the nature of protest fiction and why it assumes the form it does, it is clear that he would rather protest fiction change its narrative style and adopt a literary technique worthy of artistic merit such fiction, he feels, should revert to the storytelling tradition. He is, of course, not saying that their works should totally be devoid of politics. After all, politics shapes social behaviour, and literature is historically induced social behaviour. Terry Eagleton, whose works one must assume Ndebele has read, given the similarity of artistic perception, writes:

The task of theatre is not to "reflect" a fixed reality, but to demonstrate how character and action are historically processed, and so how could they have been, and still be, different. The play, therefore, becomes a model of that process of production, it is less a reflection of, than a reflection on, social reality (1987:65).

This, Ndebele would readily ascertain, is what makes writers like Yasher Kemal, Dikobe and others, great artistic writers. Their works, he would point out; form a "unified totality". Eagleton, in furthering his Marxist perceptions of great art and artists, pointed out:

The greatest artists are those who can recapture and recreate a harmonious totality of human life. In a society where the general and the particular, the conceptual and the sensuous, the social and the individual are increasingly torn apart by the "alienations" of capitalism, the great writer draws these dialectically together into a complex totality. His fiction thus mirrors in microcosmic form, the complex totality of society itself (1987:28).

\section{The 'Spectecular' Defined}

As stated above, in most of his critical writings Njabulo Ndebele propagates the view that black South African writers persistently writes about the political environment and conditions in which they find themselves, and are therefore guilty of simply making 'political statements' rather than advancing an artistic perspective in their writing. He contends that in the process of doing so, they have disregarded the artistic value of literature in its more encompassing form.

Ndebele regards some black South African writings as mere documentation or some form of journalistic reporting because in it the portrayal of conventional forms of oppression and the glaring contrasts between the oppressor and the oppressed dominate the content on such a way that the reader is stereotyped in his reading of a text. This type of writing, he contends, is openly concerned with what can be seen and that thinking is secondary to seeing. Ndebele goes on to call this type of writing a writing that is pre-occupied with the spectacular. In the paper entitled "The Rediscovery of the Ordinary" Some New Writings in South Africa" he develops a detailed argument on the concept of the spectacular and summarises its characteristics in this context:

The spectacular documents; it indicts implicitly; it is demonstrative, preferring exteriority to interiority; it keeps the larger issues of society in our minds, obliterating the details; it provokes identification through recognition and feeling rather than through observation and analytical thought; it calls for emotion rather conviction; it establishes a vast sense of presence without offering intimate knowledge; it confirms without necessarily offering a challenge. It is the literature of the powerless identifying the key factors responsible for their powerlessness. Nothing beyond this can be expected of it (Ndebele, 1991:46)

Before I discuss Ndebele's concept of the spectacular in detail I would like to digress slightly and try and trace where Ndebele's present critical orientation began. I should also point out here that the parallels I shall draw between his critical discourse and that of those I shall mention may be incidental insofar as Ndebele criticism is concerned. But as the old adage goes, there is no house without a foundation; Ndebele must surely have developed his critical perceptions by drawing on other existing similar criticisms.

On the issue of the spectacular, though the term is not used as such, and some writers' almost obsessive tendency to echo their own personal sentiments in their own writings, Ngara, the Zimbabwean critic, quotes Engels extensively in denunciation of those writers. In a letter he wrote to Minna Kantsky Engels states that:

The socialist novelist does not have to declare openly his ideological position, and does not have to provide a solution to the problems of his day. All a socialist novel needs to do is shake the optimism of the bourgeoisie and instil doubt as to the external validity of their assumptions (1987:10)

This is exactly Ndebele's point differently expressed. Ndebele's problem with black South African writers is that they portray their characters and situations in a spectacular manner and leave very little to the reader's imagination. According to him they also project their own personal opinions in their literary works. This Engels rejects thus: "the more the opinions of the author remain hidden, the better for the work of art" (1987:10). 
In emphasising this point Ngara quotes Engels further in a letter he wrote about his observations on Minna Kantsky's The Old Ones and the New. He wrote: "You obviously felt a desire to take a public stand in your book, to testify to your convictions before the entire world. This has now been done; it is a stage you have passed through and need not repeat in this form" (1987:1)

This should not be construed to mean that Engels, or Ndebele, are opposed to "partisanship in literature". On the contrary, they both strongly feel that art should subscribe to and be a vehicle of a particular ideology as it deals unavoidably with the condition of man and his experiences. What they are both opposed to is the method employed by the writers who project their cases so unmistakeably in their novels and that in their hast to do this they overlooked an essential pre-requisite of aesthetic art: the presentation of art in a complex manner which reflects the wide variety of man's experiences rather than a literary art form which dwells on a particular experience of man.

Brenda Cooper, after arguing her point about the nature of the novel, conclusively spells out that:

Great fiction is both progressive (in that it opposes the dominant imperialist, racist and patriarchal culture and also complex in that it does so with an awareness of the many dimensions of life and death). It does these things with an awareness that nothing is won easily and without cost (1992:180).

Ndebele traces spectacular representation in the Black South African to early writings of the likes of la Guma and Dlomo. He attributes this type of writing to the visible social fabric of South African life. He notes this in a paper entitled: 'Rediscovery of the Ordinary', wherein he writes:

The history of black South African literature has largely been the history of the representation of the spectacular. The visible symbols of the overwhelmingly oppressive South African social formation appear to have prompted over the years the development of a highly dramatic, highly demonstrative form of literary representation (1991:37)

He goes on to conclude in this regard that "it could be said, therefore, that the most outstanding feature of South African oppression is its brazen exhibition of openness" (1991:37). Ndebele clearly understands why South African writers write in the case-stating manner as they do since he attributes this to the nature of the South African social formation. He is, however, opposed to this form of literary representation as he warns that it tends to trap the writer and his literary creation in a repetitive cycle which allows no scope for creative development and artistic emancipation. Ndebele also notes in his evaluation of the history of spectacular representation that:

The stories of R.R.R. Dlomo, for example, are characterized by tightness of plot, emphasis on the most essential items of plot, the predominance of dialogue, and sudden, almost unexpected shocking endings, all of which are the ingredients of dramatic writing. Dlomo is interested only in the outward, obvious signs of individual or social behaviour... There is very little attempt to delve into intricacies of motive or social process. People and situations are either very good or very bad (1991:39).

Dlomo's writing, like that of those Ndebele currently criticizes, is a representation of "the spectacle of excess". In the same paper, Ndebele sharply contrasts the writers he criticizes with 'Joel Matlou. He uses Matlou's story "Man Against Himself" as "the very antithesis" of spectacle because it has the sense of the ordinary. It is a typical story about a man who goes to look for work at a mine and in a typical South African fashion undergoes suffering and humiliation. But, according to Ndebele, despite the humiliating exploitation he 'emerges from the entire experience feeling triumphant'. Ndebele quotes his remarks when he receives his meagre pay:

'The money was ninety-six rand. It was for my own work. I risked my life and reason for it'. And as he is leaving the money, returning home, his money in his pocket, he thinks: I just thrust it (the money) into my empty pocket and walked out of the main gate towards the bush to free myself. That time was not endless but everlasting. The earth was once supposed to be flat. Well, so it is, from Hlatini to Northam. That fact does not prevent science from proving that the earth as a whole is spherical. We are still at the stage that life, too, is spherical and much more extensive than the hemisphere we know. (1991:51)

Ndebele goes on to explain that "the significance of this story is that the writer has given us an honest rendering of the subjective experiences of his character. There is no unearned heroism here; instead there is the unproclaimed heroism of the ordinary person (1991:53). It is clear here, Ndebele asserts, that Matlou is not concerned or pre-occupied with mere surface representation.

As pointed out earlier on, Ndebele is mostly worried about the form that protest fiction assumes, namely, its preoccupation with "mechanical surface representation". This assertion is also prompted by his belief that protest fiction is always about the writer's obsessive fascination with his immediate political situation - which is a bad situation in most cases - and his inability to adapt his craft to an appreciable aesthetic literary from, resorts to making accusations and 
presenting 'evidence' of his political condition.

Ndebele also argues that because protest fiction is on the whole a portrayal of bitterness in an urban setting, it tends to simply propagate a strong political statement of simply it tries to invoke pity from the white man. This by drawing his attention to the plight of the black man as portrayed in a novel. All this in the hope that the white man will reflect on himself and change his wicked ways. Ndebele points out that all this is a fruitless exercise which is bound to have unintended repercussions.

By rejecting the preponderance of the spectacle it appears that Ndebele's real argument against protest fiction writers is what he perceives to be their disregard of "storytelling" as the basis of creativity in their works. To him the tradition must be that of art rooted "in the history of storytelling". He asserts this by quoting Walter Benjamin in "Turkish Tales... as having observed that:

Experience which is passed from mouth to mouth is the source from which all storytellers have drawn. And among those who have written the tales, it is the great ones whose versions differ least from the speech of the many nameless storytellers (1984:10).

Ndebele is not alone in his observation that black South African fiction is awash with the spectacle of daily living in South Africa and that writers should tell stories rather than simply document their observations. Michael Vaughan, in total agreement with Ndebele on this point, writes in a paper titled "The writer as a Storyteller":

The writer as storyteller... is precisely the writer who acknowledges the creativity of the people as 'makers of culture'. The writer can only succeed as a storyteller who enters into a committed, validating relationship with popular beliefs and customs. Such a writer may attempt to initiate change in these popular conditions, but only on the basis of an imaginative comprehension of them (1988:24).

In emphasizing this point, Vaughan, in a paper titled 'storytelling in Politics and Fiction' asserts about protest fiction writers that:

\begin{abstract}
Instead, in order to provide their stories with the desired critical character, they resort to sloganizing and to a journalistic rather than a storytelling mode of narrative, presenting the reader with "evidence" of the cruelty of apartheid rather than composing a thought provoking story (1990:187).
\end{abstract}

In this case Vaughan, like Ndebele, clearly sees the spectacles as the direct opposite of, and devoid of a storytelling mode. The spectacular becomes unnecessary and the ordinary's infusion in a storytelling mode makes great literary art.

\title{
5. In Closing
}

To go back to my earlier argument on liberal-humanism, one is reminded here of the nature of the concept. It occurs to me that liberal humanist literature, like protest fiction, despite their different styles of literary projection, is similar in their limited, stereotyped forms. Whereas "liberal-humanists texts privilege the centre, emphasizing the "home" over the "native", the "metropolitan" over the "colonial", protest fiction emphasizes 'the obvious' and politics over artistic complexity. Artistic stereotyping is a sure way of diminishing the artistic worthiness of literary works because surely, such works will be so bare and open that they will need no interpretation. After all, these works express themselves in such a way as to leave the reader in do doubt their intention. I shall end here by quoting Alex Comfort in 'The Novel and Our Time', wherein he writes in a manner of propagating a fundamental aspect of the novel. He writes: Interpretation rather than an attempt to convince is the chief object of art (1948:80).

\section{References}

Banghor, M. 2004. Exploring literariness. Johannesburg: COSAW. Comfort, A. 1948. The Novel in our Time. Phoenix: Phoenix House.

Cooper, B. 1992. To Lay These Secrets Open: Evaluating African Literature. Cape Town: David Phillip.

Eagleton, T. 1983. Literary Theory: An Introduction. Oxford: Blackwell Ltd.

Ndebele, N. 1991. Rediscovery of the Ordinary: Essays on South African Literature and Culture. Johannesburg: COSAW.

Ndebele, N. 1984. "Turkish Tales and Some Thoughts on South African Fiction". Staffrider, Vol. 6, No.1.

Ngara, E. 1987. Art and Ideology in the African Novel. London: Heinemann.

Vaughan, M. 1988. "The Writer as Storyteller?" African Studies Seminar paper, March. 